\title{
Variable expression of cerebral cavernous malformations in carriers of a premature termination codon in exon 17 of the Krit I
} gene

\author{
Miguel Lucas*1, Alzenire F Costa ${ }^{1}$, José M García-Moreno ${ }^{2}$, Francisca Solano ${ }^{1}$, \\ Miguel A Gamero ${ }^{2}$ and Guillermo Izquierdo ${ }^{2}$
}

Address: ${ }^{1}$ Molecular Biology Services of the Virgen Macarena University Hospital. Avda Dr. Fedriani sn, 41009 Sevilla, Spain and ${ }^{2}$ Neurology Services of the Virgen Macarena University Hospital. Avda Dr. Fedriani sn, 41009 Sevilla, Spain

Email: Miguel Lucas* - lucas@us.es; Alzenire F Costa - alzenira@yahoo.com; José M García-Moreno - sinue@arrakis.es;

Francisca Solano - paquisol@hotmail.com; Miguel A Gamero - magam@supernet.es; Guillermo Izquierdo - ayuso@arrakis.es

* Corresponding author

This article is available from: http://www.biomedcentral.com/l47I-2377/3/5

(C) 2003 Lucas et al; licensee BioMed Central Ltd. This is an Open Access article: verbatim copying and redistribution of this article are permitted in all media for any purpose, provided this notice is preserved along with the article's original URL.

\begin{abstract}
Background: Cerebral cavernous malformations (CCM) present as either sporadic or autosomal dominant conditions with incomplete penetrance of symptoms. Differences in genetic and environmental factors might be minimized among first-degree relatives. We therefore studied clinical expression in a family with several affected members.

Methods: We studied a three-generation family with the onset of CCM as a cerebral haemorrhage in the younger (four-year-old) sibling. Identification and enumeration of CCMs were performed in T2-weighted or gradient-echo MRIs of the whole brains. Genetic analysis comprised SCCP, sequencing and restriction polymorphism of the Kritl gene in the proband and at risk relatives.

Results: The phenotypes of cerebral cavernous malformations (CCMs) in carriers of Kritl mutations were very variable. We identified a novel frameshift mutation caused by a 1902A insertion in exon 17 of the Krit l gene, which leads to a premature TAA triplet and predicts the truncating phenotype Y634X. A very striking finding was the absence of both clinical symptoms and CCMs in the eldest sibling harbouring the 1902insA.

Conclusions: Patients in this family, harbouring the same mutation, illustrate the very variable clinical and radiological expression of a Kritl mutation. The early and critical onset in the proband contrasts with minor clinical findings in affected relatives. This consideration is important in genetic counselling.
\end{abstract}

\section{Background}

Cerebral cavernous malformations (CCM) are enlarged capillary cavities without alterations in the surrounding brain parenchyma. Studies based on necropsy and magnetic resonance imaging indicate a prevalence in the general population close to $0.1-0.5$ percent. CCMs present as either sporadic or autosomal dominant conditions with incomplete penetrance of symptoms such as epilepsy, headaches, seizures and cerebral haemorrhage. Neuroimaging penetrance of CCMs is much higher than clinical penetrance and almost $60 \%$ of at-risk relatives are symptom-free in spite of having MRI lesions [1]. Sporadic CCM 
is characterised by a single cavernous angioma, whereas images of multiple lesions are found in inherited CCM [1].

Mutations causing premature termination triplets in $C C M 1$, the gene encoding the Krit1 protein, cause hereditary cavernous angiomas $[2,3]$, and a germline mutation in the KRIT1 gene has been reported to cause multiple lesions in one CCM patient [4]. A great variety of mutations have been described [5], including a redundant mutation in Hispano-Mexican families corresponding to a chromosomal haplotype that is not shared by patients of Spanish extraction [6].

The Krit 1 protein was identified by its interaction with Rap1A, a small Ras like GTPase [7]. Four novel coding exons and other non-coding exons have been described by computational and experimental analyses [8,9]. KRIT1 encodes a 736 amino-acids protein containing four ankyrin domains, a FERM domain and a C-terminal portion that interacts with Rap1A. The four novel exons encode an N-terminal region containing an NPXY motif that is required for interaction of with icap $1 \alpha$, a modulator of $\beta 1$ integrin [10,11].

We report a mutation causing a premature termination triplet in exon 17 of the Krit1 gene in a family with diagnoses of cerebral cavernous angioma. The early onset in the proband contrasts with minor symptoms in relatives who are carriers of the mutation. Particularly striking is the absence of CCMs in the eldest sibling.

\section{Methods}

\section{Patients}

The onset of the disease in this family was a cerebral haemorrhage in the younger sibling, the 4-year-old proband. The family comprises a three-generation pedigree with minor neurological symptoms in the antecedents. Antecedents were assessed by a retrospective clinical study that revealed three asymptomatic siblings and nonspecific symptoms in other affected relatives (his sister and grandmother) who complained about headaches. Identification and enumeration of CCMs were performed in T2-weighted or gradient-echo MRIs of the whole brains.

\section{Genetic analysis}

CCM1 haplotypes of individuals of the CVE10 family were analyzed using the protocols and primers of a set of polymorphic microsatellite markers spanning the CCM1 interval, as previously described [12].

A fragment of the Krit1 gene containing exon 17 was PCRamplified with forward (5'TGGTACATTTTCCTTTCA) and reverse (5'TGACATGATTGGTAAAAA) primers. The nomenclature of the cDNA refers to the full length KRIT1 cDNA in GenBank (accession number AF296765). Genomic DNA was initially screened by analysis of SSCP. PCR fragments were denatured at $95^{\circ} \mathrm{C}$ for $5 \mathrm{~min}$, ice chilled, and separated by electrophoresis in 10\% acrylamide-bisacrylamide (37.5:1) gels containing $10 \%$ glycerol without urea.

Sequencing of exon 17 was carried out in genomic DNA by the terminal dideoxynucleotide method. Automated sequence analyses of both the sense and antisense strands were done with 5'-labeled IRD800 primers according to the protocols of the SequiTherm kit (Epicentre Technologies, Madison, Wisconsin). Polyacrylamide gel electrophoresis and analysis of the sequencing fragments were performed in a LI-COR DNA4000 sequencer with the software provided by the manufacturer (LI-COR Inc, Lincoln, Nebraska, Canada).

Table I: Location and number of cerebral malformations. MRIs were obtained with echo-gradient sequences except the T2-weighted images of patient I-I. Individual II-5 is the proband's uncle, not shown in figure I, who harbours the I902insA mutation. MRIs of sibling III-2 were repeatedly negative and therefore he was excluded from the table.

\begin{tabular}{|c|c|c|c|c|c|c|c|}
\hline & I-I & II-I & II-5 & III-3 & III-4 & III-5 & $\%$ \\
\hline Age & 82 & 46 & 52 & 15 & 11 & 4 & \\
\hline Onset age & 67 & --- & 39 & --- & 9 & 4 & \\
\hline Symptoms & Headache & None & Hemorrhage & none & Headache & Hemorrhage & \\
\hline Total & 34 & 51 & 37 & 5 & 9 & 8 & 100 \\
\hline Frontal & 8 & 21 & 14 & 1 & 1 & 1 & 32 \\
\hline Parietal & 10 & 12 & 10 & 1 & I & 2 & 25 \\
\hline Temporal & 4 & 8 & 6 & 2 & 2 & 4 & 18 \\
\hline Occipital & 5 & 5 & 3 & 0 & 4 & 0 & 12 \\
\hline Diencephalon & 0 & 1 & I & 1 & 0 & 0 & 2 \\
\hline Midbrain & I & 0 & 0 & 0 & 0 & 0 & 0.7 \\
\hline Pons & 0 & I & I & 0 & I & 0 & 2 \\
\hline Medulla & 0 & 1 & 0 & 0 & 0 & 0 & 0.7 \\
\hline Cervical & 6 & 2 & 2 & 0 & 0 & I & 7.6 \\
\hline
\end{tabular}




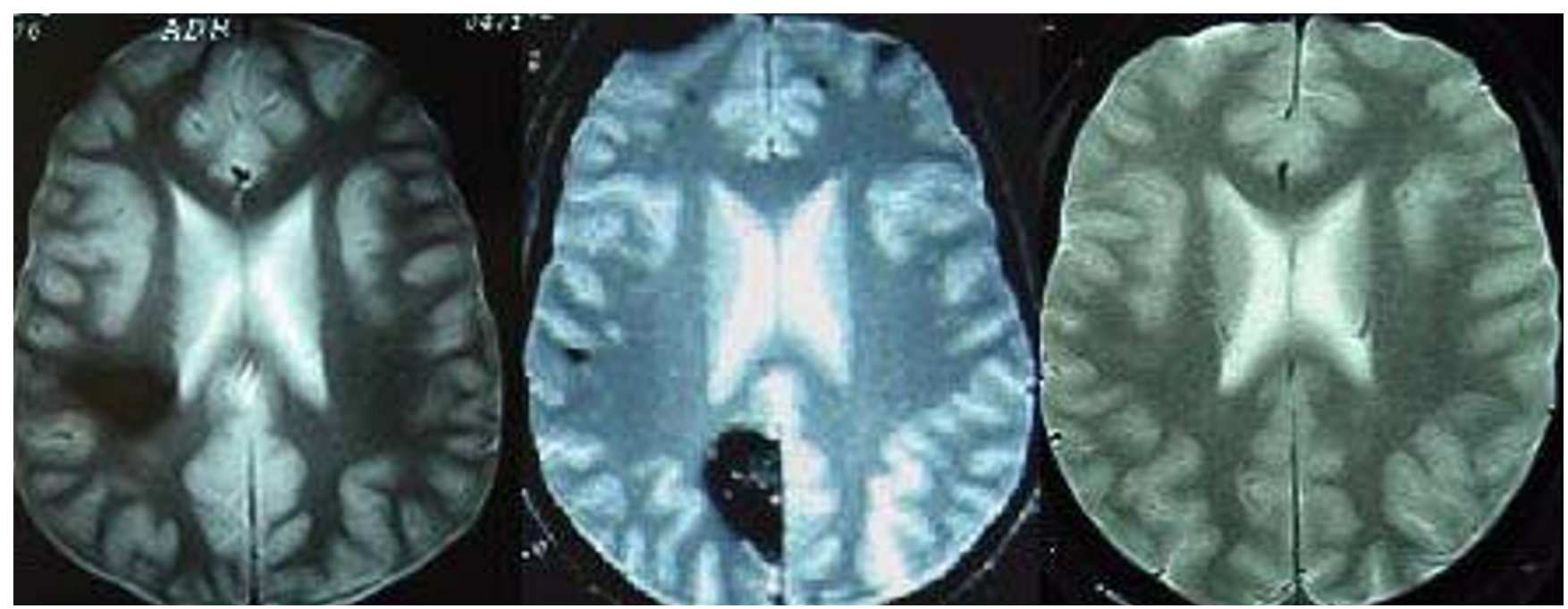

\section{Figure I}

MRIs of CCMs. The echo gradient sequences of the proband (left), grandmother (middle) and the older brother (right) harbouring the Y634X mutation (III-2 in figure 3). Note the typical images of cavernous malformation and the absence of lesions in III2 , the asymptomatic carrier of the 1902 insA.

\section{Results}

The onset of cerebral hemorrhage in the 4-year-old proband was the main clinical finding in the CVE10 family. The retrospective study of siblings and parents showed minor symptoms though one sibling had epilepsy. The clinical study was completed with MRI scans of consenting symptomatic and asymptomatic at-risk first-degree relatives. Multiple CCMs were observed in the MRIs of the grandmother, mother and two of the siblings and therefore familial characteristic was confirmed (see table 1 and figure 1 for details of number and locations of CCMs). The number of CCMs in patients of this pedigree was related to age with a ratio around 0.9 (range 0.3-2) and no significant differences in location were observed. Comparison of CCM locations is weakened because there were far fewer malformations in the younger patients (table 1).

Haplotyping of markers of the locus demonstrated segregation linkage of this family to CCM1. The affected individuals, i.e. those with CCMs in MRIs, shared the same grandmother's chromosome. It is worth noting that the asymptomatic sibling III-2 shares the linked haplotype, without apparent recombination, but his MRI showed no CCMs. Sequencing of the forward and reverse strands of the proband demonstrated an exonic A/T insertion at position 1902 leading to a premature TAA termination codon and the predicted phenotype Y634X. The 1902A insertion and the ambiguities of the overlapping strands were identified in both the sense and antisense strands. The nucleotide insertion at this position originates a TTAA
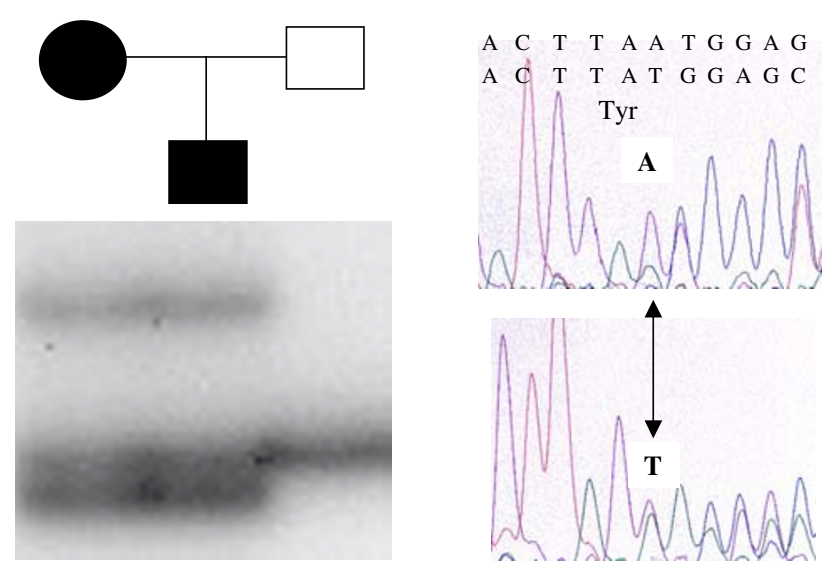

\section{Figure 2}

Left panel, SCCP of the proband and parents of CVEIO PCR was performed with the reaction mixture supplemented with [ $\left.\alpha^{32} \mathrm{P}\right]-d C T P$. Aliquots of the product were run in acrylamide gels (see Methods) and revealed by auto-radiography. Right panel, chromatogram of the 1902InsA. Traces of the sense (upper) and antisense (lower) DNA strands of the proband. The wild type and mutated nucleotide sequences and the aminoacid change are indicated over the sense strand. The sequence shows the site of the 1902insA mutation (see arrow) and the frameshift. The ambiguities are caused by the overlapping bands of the wild type and mutated strands due to the nucleotide insertion. The stop TAA triplet predicts a truncating protein with the changed phenotype Y634X. 


\begin{tabular}{|c|c|c|c|c|c|c|c|c|c|c|c|c|c|c|c|c|c|}
\hline \multicolumn{2}{|c|}{ I-1 } & \multicolumn{2}{|c|}{ I-2 } & \multicolumn{2}{|c|}{ II-1 } & \multicolumn{2}{|c|}{ II-2 } & \multicolumn{2}{|c|}{ III-1 } & \multicolumn{2}{|c|}{ III-2 } & \multicolumn{2}{|c|}{ III-3 } & \multicolumn{2}{|c|}{ III-4 } & \multicolumn{2}{|c|}{ III-5 } \\
\hline 221 & 219 & 221 & 219 & 221 & 221 & 219 & 221 & 221 & 221 & 221 & 219 & 221 & 219 & 221 & 219 & 221 & 219 \\
\hline 127 & 127 & 127 & 127 & 127 & 127 & 127 & 125 & 127 & 125 & 127 & 127 & $1 \longdiv { 1 2 7 }$ & 127 & 127 & 127 & 127 & 127 \\
\hline \begin{tabular}{|l|}
129 \\
\end{tabular} & 133 & 139 & 139 & $\mid \overline{129}$ & 139 & 133 & 129 & 139 & 129 & 129 & 133 & $\mid 129$ & 133 & $\mid 129$ & 133 & $\mid 129$ & 133 \\
\hline \begin{tabular}{|l|}
197 \\
\end{tabular} & 185 & 185 & 197 & 197 & 185 & 183 & 183 & 185 & 183 & 197 & 183 & $\mid$\begin{tabular}{l|l|}
197 \\
\end{tabular} & 183 & \begin{tabular}{|l|}
197 \\
\end{tabular} & 183 & $\mid$\begin{tabular}{|l|}
197 \\
\end{tabular} & 183 \\
\hline \begin{tabular}{|l|}
107 \\
107
\end{tabular} & 107 & 103 & 103 & 107 & 103 & 103 & 103 & 103 & 103 & 107 & 103 & $\mid \frac{171}{107}$ & 103 & 107 & 103 & $\mid$\begin{tabular}{|l|}
107 \\
\end{tabular} & 103 \\
\hline \begin{tabular}{|l|}
127 \\
\end{tabular} & 127 & 131 & 129 & 127 & 131 & 127 & 127 & 131 & 127 & $\frac{17}{127}$ & 127 & 127 & 127 & 127 & 127 & $\frac{1127}{127}$ & 127 \\
\hline 127 & 273 & 273 & 275 & $\frac{1121}{275}$ & 273 & 273 & 273 & 273 & 273 & $\frac{121}{275}$ & 273 & $\frac{121}{275}$ & 273 & $\mid \frac{121}{275}$ & 273 & 101 & 273 \\
\hline$\frac{275}{149}$ & 147 & 151 & 151 & $\frac{2 / 5}{149}$ & 151 & 151 & 145 & 151 & 145 & $\frac{2 / 5}{149}$ & 151 & $\frac{2 / 3}{149}$ & 151 & $\frac{2 / 3}{149}$ & 151 & $\frac{2 / 3}{149}$ & 151 \\
\hline & & & & & & & & & & & & & & & & & \\
\hline
\end{tabular}
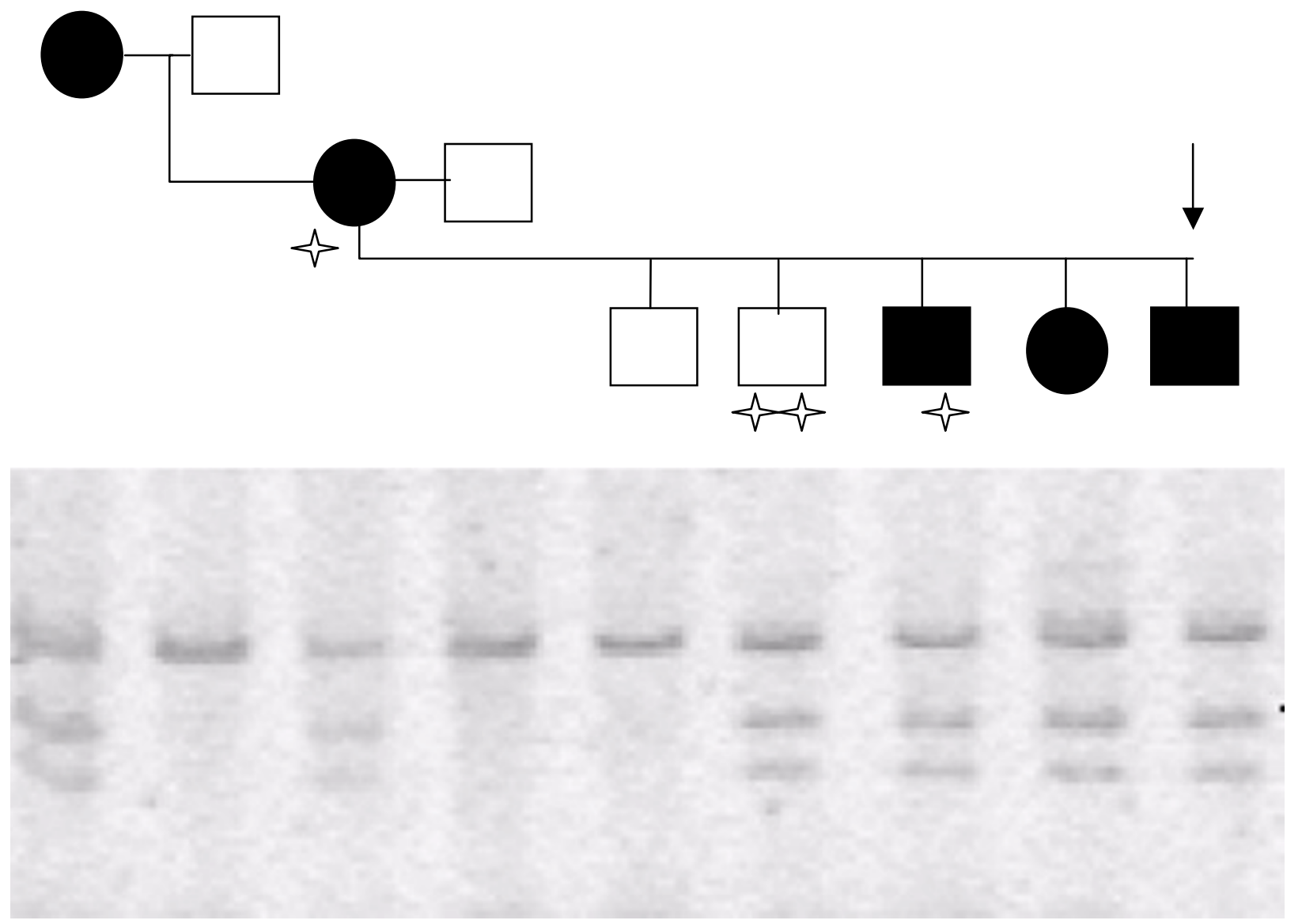

\section{Figure 3}

Haplotypes and restriction fragment polymorphism (RFLP). Haplotypes were analysed using the markers surrounding CCMI as described in Methods. The markers from top to bottom were: D7S2409, D7SI8I3, D7S1789, D7S646, D7S558, D7S689, D7S652 and D7S492. Exon 17 was amplified with the primers and aliquots of the PCR were digested overnight at $37^{\circ} \mathrm{C}$ with Msel. The fragments were separated in an $8 \%$ polyacrylamide gel containing urea and, after staining with ethidium bromide, the gel was photographed under UV. The undigested product is $297 \mathrm{pb}$ long and the fragments separated from the TTAA restriction site are 158 and $139 \mathrm{pb}$. Therefore, individuals harbouring the 1902insA mutation have three fragments of 297, 158 and 139 bp. Filled symbols in the pedigree refer to patients with CCMs in the echo-gradient MRIs. Arrow indicates the proband. Stairs refer to asymptomatic carriers of the mutation. The double stair denotes the asymptomatic carrier with MRIs free of CCMs 
restriction. This is recognised by the MseI endonuclease that splits the $297 \mathrm{bp}$ PCR product into 158 and $139 \mathrm{bp}$. The RFLP of exon 17 in affected CV10E individuals demonstrated a heterozygous polymorphism of 297, 158 and $139 \mathrm{bp}$. Here again, the second brother (individual III-2 in the pedigree) had the mutated polymorphism although his MRI was free of CCMs. There is a complete coincidence of the CCM-linked haplotype with the mutated RFLP in this pedigree (see figure 3). Analysis of the chromosomes of 80 healthy individuals (not shown) coincided with the wild type RFLP.

\section{Discussion}

Hereditary forms of CCM, in contrast to sporadic forms that are characterized by single lesions, present as multiple malformations and, frequently, two or more relatives are affected [1]. This family illustrates the very variable clinical phenotype of cavernous malformations since the proband is the younger sibling suffering a cerebral hemorrhage. This early and critical onset contrasts with the minor symptoms observed in the affected relatives, even in the 82-year-old grandmother, notwithstanding the multiple cerebral lesions. However, the most striking finding was that repetitive studies of brain images of the III-2 sibling, who is 18 years old, demonstrated no malformations in spite of the presence of the 1902A insertion. The absence of cavernous malformations in echogradient sequences in this sibling was confirmed by MRIs of the spinal cord and the genetic status was corroborated by the inheritance of the haplotype harbouring the mutation and its illustration with MsI restriction polymorphisms. Nonetheless small CCMs, undetectable even on gradient echo sequences, could still be present in the eldest sibling and might develop later.

Several mutations in exon 17 of the Krit1 gene associated with CCMs have been described [5]. The Y634X mutation modifies the FERM sequence in the last residues (IPTYGAA), which are replaced by YPT*WSS, indicating the potential pathogenic mechanism of the FERM domain. The report of a novel N-terminal region in Krit1 containing an NPXY motif interacting with icap $1 \alpha$, a modulator of $\beta 1$ integrin, and the presence of a FERM domain in Krit1, have suggested that this protein might be involved in bi-directional signaling between the integrin and the cytoskeleton [11].

Penetrance of Krit1 mutations has not been properly studied but significant locus-specific differences in penetrance have been identified. The penetrance of clinical CCMs among apparent carriers in kindreds linked to CCM1, CCM2 and CCM3 have been estimated as 88, 100 and $63 \%$ respectively [13]. Individuals usually become symptomatic between 20 and 40 years of age, although clinical signs have been described in all age groups $[1,5]$.
Asymptomatic carriers are probably not an unusual finding, but the demonstration of the mutation is necessary to raise this conclusion and for genetic counselling. CCMs may develop in utero decades before any clinical presentation [3] but it is possible that penetrance varies among families with particular mutations at each gene. Small cavernomas could be present in the eldest sibling of the family studied here and may develop later. Nonetheless, the variable clinical and radiological traits in affected individuals of the same family exclude a direct correlation between clinical expression and genotype. The affected siblings, in addition to the Y634X mutated phenotype, share the same paternal chromosome, so a variable genetic background, at least in the vicinity of CCM1, can be excluded.

Assuming a pathogenic mechanism similar to the doublehit hypothesis of tumorigenesis and given the multiplicity of lesions, a very potent susceptibility to genetic or environmental factors is required to cause the multiplicity of somatic events. Differences in genetic and environmental factors are presumably minimal among first-degree relatives and therefore cannot easily explain the variable clinical and radiological expression. In addition to genetic and environmental causes, epigenetic factors and other mechanisms, i.e. non-sense mRNA decay, can be considered in the pathogenesis of CCM.

\section{Conclusions}

Patients in this family, harbouring the same mutation and chromosomes, are illustrative of the very variable clinical and radiological expression of a Krit 1 mutation. The early and critical onset in the proband contrasts with minor clinical findings in the affected relatives. This consideration is important in genetic counselling.

\section{Competing interests}

None declared.

\section{Authors' contributions}

ML conceived and coordinated this study, analysed the DNA sequences, designed the RFLP analysis and drafted the manuscript. AFC carried out the SCCP and sequencing reactions. FS carried out the haplotypes and the restriction polymorphisms. JMG-M, MAG and GI contributed and coordinated the clinical and MRI studies of patients.

All authors read and approved the final manuscript

\section{Acknowledgements}

Written consent was obtained from the patient or their relative for publication of the patient's details. Supported by grant 99/0407 from the Fondo de Investigaciones Sanitarias de la Seguridad Social and 19/02 from Servicio Andaluz de Salud. 


\section{References}

I. Labauge P, Laberge S, Brunereau L, Levy C and Tournier-Lasserve E: Hereditary cerebral cavernous angiomas: clinical and genetic features in $\mathbf{5 7}$ French families Lancet 1998, 352:1892-1897.

2. Laberge-le Couteulx S, Jung $\mathrm{HH}$, Labauge $\mathrm{P}$, Houtteville JP, Lescoat $\mathrm{C}$, Celillon M, Marechal E, Joutel A, Bach JF and Tournier-Lasserve E: Truncating mutations in CCMI, encoding KRITI, cause hereditary cavernous angiomas Nat Genet 1999, 23:189-193.

3. Sahoo T, Johnson EW, Thomas JW, Kuehl PM, Jones TL, Dokken C, Touchman JW, Gallione C], Lee-Lin SQ , Kosofsky B, Kurth JH, Louis DN, Mettler G, Morrison L, Gil-Nagel A, Rich SS, Zabramski JM, Boguski MS, Green ED and Marchuk DA: Mutations in the gene encoding KRITI, a Krev- I/rap I a binding protein, cause cerebral cavernous malformations (CCMI) Hum Mol Genet 1999, 8:2325-2333.

4. Lucas M, Costa AF, Montori M, Solano, Zayes MD and Izquierdo G: Germline mutations in the CCMI gene, encoding KRITI, cause cerebral cavernous malformations Ann Neurol 200I, 49:529-532.

5. Verlaan DJ, Davenport WJ, Stefan H, Sure U, Siegel AM and Rouleau G: Cerebral cavernous nalformations. Mutations in Krit I Neurology 2002, 58:853-857.

6. Lucas M, Solano F, Zayas MD, Garcia-Moreno JM, Gamero MA, Costa $\mathrm{AF}$ and Izquierdo $\mathrm{G}$ : Spanish families with cerebral cavernous angioma do not bear 742C $\rightarrow$ T Hispanic American mutation of the KRITI gene Ann Neurol 2000, 47:836.

7. Serebriiskii I, Estojak J, Sonoda G, Testa JR and Golemis EA: Association of Krev-I/rap Ia with KRITI, a novel ankyrin repeatcontaining protein encoded by a gene mapping to 7q2I-22 Oncogene 1997, I 5:1043-1049.

8. Zhang J, Clatterbuck RE, Rigamonti D and Dietz HC: Cloning of the murine Krit I cDNA reveals novel mammalian 5' coding exons Genomics 2000, 70:392-395.

9. Sahoo T, Goenaga-Diaz E, Serebriiskii IG, Thomas, Kotova E, Cuellar JG, Peloquin JM, Golemis, Beitinjaneh F, Green ED, Johnson EW and Marchuk DA: Computational and experimental analyses reveal previously undetected coding exons of the KRITI (CCMI) gene Genomics 200I, 7 I:123-126.

10. Zhang J, Clatterbuck RE, Rigamonti D, Chang DD and Dietz HC: Interaction between Krit I and Icapl infers perturbation of integrin $\beta \mathrm{I}$-mediated angiogenesis in the pathogenesis of cerebral cavernous malformation Hum Mol Genet 200I, I 0:2953-2960.

II. Zawistowski JS, Serebriiski IG, Lee MF, Golemis EA and Marchuk DA: Krit I association with the integrin-binding protein icap I: a new direction in the elucidation of cerebral cavernous malformations (CCMI) pathogenesis Hum Mol Genet 2002, I I:389-396.

12. Jung $H H$, Labauge $P$, Laberge $S$, Marechal E, Tournier-Lasserve E, Lucas M, Garcia-Moreno JM, Gamero MA, Izquierdo G and TourinerLasserve E: Spanish families with cavernous angiomas do not share the Hispano-American CCMI haplotype J Neurol Neurosurg Psychiatry 1999, 67:551-552.

13. Craig HD, Gunel M, Cepeda O, Johnson EW, Ptacek L, Steinberg GK, Ogilvy CS, Berg MJ, Crawford SC, Scott RM, Steichen-Gersdorf E, Sabroe R, Kennedy CT, Mettler G, Beis MJ, Fryer A, Awad IA and Lifton RP: Multilocus linkage identifies two new loci for a mendelian form of stroke, cerebral cavernous malformation, at 7p I5-I3 and 3q25.2-27 Hum Mol Genet 1998, 7:185I-I858.

\section{Pre-publication history}

The pre-publication history for this paper can be accessed here:

http://www.biomedcentral.com/1471-2377/3/5/prepub
Publish with Bio Med Central and every scientist can read your work free of charge

"BioMed Central will be the most significant development for disseminating the results of biomedical research in our lifetime. "

Sir Paul Nurse, Cancer Research UK

Your research papers will be:

- available free of charge to the entire biomedical community

- peer reviewed and published immediately upon acceptance

- cited in PubMed and archived on PubMed Central

- yours - you keep the copyright

Submit your manuscript here:

http://www.biomedcentral.com/info/publishing_adv.asp
BioMedcentral 